\title{
Evaluation of an FFQ for assessment of antioxidant intake using plasma biomarkers in an ethnically diverse population
}

\author{
Allison M Hodge ${ }^{1,2, *}+$, Julie A Simpson ${ }^{1,2}$, Masha Fridman ${ }^{1}$, Kevin Rowley ${ }^{3}$, \\ Dallas R English ${ }^{1,2}$, Graham G Giles ${ }^{1,2}$, Qing Su ${ }^{4}$ and Kerin $\mathrm{O}^{\prime} \mathrm{Dea}^{4,5}$ \\ ${ }^{1}$ Cancer Epidemiology Centre, The Cancer Council Victoria, Melbourne, Australia: ${ }^{2}$ Centre for Molecular, \\ Environmental, Genetic and Analytic Epidemiology, School of Population Health, University of Melbourne, \\ Melbourne, Australia: ${ }^{3}$ Onemda VicHealth Koori Health Unit, Centre for Health and Society, School of \\ Population Health, University of Melbourne, Melbourne, Australia: ${ }^{4}$ Baker Heart Research Institute, Melbourne, \\ Australia: ${ }^{5}$ Department of Medicine, University of Melbourne, St Vincent's Hospital, Melbourne, Australia
}

Submitted 16 August 2007: Accepted 20 February 2009: First published online 16 April 2009

\begin{abstract}
Objective: To evaluate FFQ estimates of dietary intake of individual antioxidants, fruit and vegetables in comparison to plasma concentrations of each antioxidant, and to determine which individual foods are associated with plasma antioxidant concentrations.

Design: Dietary ( $\alpha$-carotene, $\beta$-carotene, $\beta$-cryptoxanthin, lutein/zeaxanthin, lycopene, retinol, and vitamin E) intakes over 12 months were estimated from a 121-item FFQ. Correlation coefficients, corrected for within-person variability in diet and plasma antioxidants, were used to examine associations between antioxidant concentrations in diet and plasma.

Setting: Melbourne Collaborative Cohort Study (MCCS).

Subjects: Men and women ( $n$ 3110) who were randomly selected from the MCCS. Participants were aged 36-72 years and were born in Australia, Greece, Italy or the UK.

Results: Correlation coefficients for the carotenoids ranged from $0 \cdot 28$ for lycopene to 0.46 for $\beta$-cryptoxanthin. There was no association between dietary and plasma retinol or dietary vitamin $\mathrm{E}$ with plasma $\alpha$ - and $\gamma$-tocopherol. Individual plasma carotenoid concentrations were associated with intakes of fruit and vegetables. Conclusions: Our data suggest that the FFQ provides useful information on intakes of each of the carotenoids: $\alpha$-carotene, $\beta$-carotene, $\beta$-cryptoxanthin, lycopene and lutein/zeaxanthin. There was no association between diet and plasma markers of retinol or vitamin E; this may reflect the importance of factors other than intake in modifying circulating levels of these nutrients.
\end{abstract}

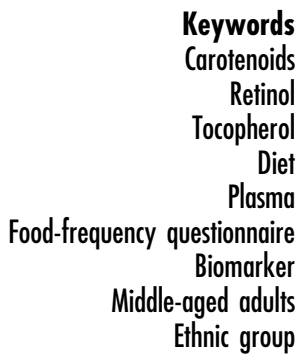

The most recent Dietary Guidelines for Australian Adults ${ }^{(1)}$ recommend eating 'plenty of vegetables, legumes and fruits'. Since the guidelines were released in 2003 the evidence has remained strong for an association with $\mathrm{CVD}^{(2)}$, while results from prospective studies have suggested that the associations seen with cancer in case-control studies may be due to bias in dietary measurements ${ }^{(3)}$. There are fewer reports of vegetables and fruit as risk factors for type 2 diabetes, but prospective studies show potential benefits from fruit and vegetables ${ }^{(4,5)}$, which may be partly due to carotenoids, many of which are strong antioxidants ${ }^{(6)}$.

Further studies are required to clarify the benefits of fruit and vegetables, especially with regard to cancer.

$\uparrow$ Correspondence address: University of Melbourne, Department of Medicine, St Vincent's Hospital, PO Box 2900, Fitzroy 3065, Australia.
Randomized controlled trials may be preferred for aetiological studies of diet and disease ${ }^{(7)}$ but, in practice, prospective studies where diet is measured before the diagnosis of disease provide the main evidence for such associations. Although FFQ are used widely in large-scale dietary studies, they measure intake with considerable error, which may contribute to the relatively weak associations seen between diet and disease in most studies. Evaluation of the error associated with FFQ is important for the interpretation of results in studies of dietary risk factors $^{(8)}$.

The Melbourne Collaborative Cohort Study (MCCS) was established to study prospectively associations between diet and chronic diseases, including common cancers such as prostate, bowel and breast cancer, type 2 diabetes and CVD, and is one of the largest prospective 
cohort studies conducted in Australia. An FFQ was developed in the late 1980s to use as the measure of baseline diet in the $\operatorname{MCCS}^{(9)}$. Our objective in the present study was to evaluate the performance of the FFQ in estimating the intakes of individual carotenoids, fruit and vegetables by comparison with biomarkers, to inform future analyses within the MCCS. Associations between retinol and vitamin $\mathrm{E}$ in diet and plasma were also assessed.

\section{Subjects and methods}

The MCCS recruited 41528 people (17049 men) between 27 and 75 years of age at baseline $(99 \cdot 3 \%$ were aged 40-69 years), including 5425 migrants from Italy and 4535 from Greece. Recruitment occurred from 1990 to 1994. The Cancer Council Victoria's Human Research Ethics Committee approved the study protocol.

For the present analysis, 4659 participants were randomly selected from the MCCS for case-cohort studies ${ }^{(10)}$ which included analysis of plasma carotenoids. Of these 4659, plasma carotenoid measurements could not be made for 1492 participants (predominantly males) because the samples were inadvertently aliquoted into inappropriate containers or the blood sample was not collected. Of the remaining 3167 participants, fifty-five people with energy intakes in the top and bottom $1 \%$ of the sex-specific distributions were excluded as we believe these extreme values reflect a poorly completed FFQ. We also excluded one participant with an extreme dietary retinol intake of $16671 \mu \mathrm{g} / \mathrm{d}$ and one with plasma retinol of $30 \mu \mathrm{mol} / \mathrm{l}$. This left 3110 participants with plasma and dietary antioxidant data.

\section{Analysis of plasma carotenoid, retinol and tocopberol concentrations}

Blood was collected from all subjects into sodium-heparin Vacutainers, and immediately protected from light. After collection, blood was centrifuged immediately and plasma was stored in the vapour phase of liquid nitrogen tanks at approximately $-120^{\circ} \mathrm{C}$. Following an average of $9.0(\mathrm{SD} 1 \cdot 2)$ years, samples for participants in the sub-cohort were selected in random order by sex and aliquoted in batches. To each batch were added 10\% plasma matrix quality control samples ${ }^{(11)}$. Samples were defrosted at room temperature, then vortexed rapidly for a few seconds and spun at $1000 \mathrm{rpm}(210 \mathrm{~g})$ for $10 \mathrm{~min}$ at $4^{\circ} \mathrm{C}$ on a Heraeus Megafuge 2.0R bench top centrifuge. Samples were kept on ice before and after they were aliquoted. Liquid nitrogen was added to the tubes, which were sealed quickly, and then frozen immediately at $-80^{\circ} \mathrm{C}$ until shipment to the laboratory in cryoboxes. All samples were handled under red light conditions. Antioxidants in plasma are stable under these conditions ${ }^{(12)}$.

Samples were assayed at the Department of Chemical Pathology, Women's and Children's Hospital, Adelaide, and Monash Medical Centre, Melbourne, using a modified gradient HPLC procedure for simultaneous quantification of lipid-soluble antioxidants - retinol, $\gamma$-tocopherol, $\alpha$-tocopherol, lutein/zeaxanthin, $\beta$-cryptoxanthin, translycopene, cis-lycopene, $\alpha$-carotene and $\beta$-carotene - as previously described ${ }^{(13)}$. Compounds for peak identification were obtained from Sigma Chemical Company (Castle Hill, Australia). HPLC-grade solvents and other reagents were obtained locally from commercial suppliers (Selby-Biolab, Melbourne, Australia).

The assay CV for the plasma matrix quality control samples ranged from $2 \%$ to $15 \%$ for control samples analysed at the Monash Medical Centre, Melbourne, and from 5\% to $19 \%$ at the Department of Chemical Pathology, Adelaide. All plasma antioxidant concentrations are expressed as $\mu \mathrm{mol} / 1$ or divided by plasma cholesterol concentration ${ }^{(14)}$.

\section{Estimation of dietary intake}

A 121-item FFQ was specifically developed for the MCCS, based on $8 \mathrm{~d}$ of weighed food records in a sample of 810 Australian-, Italian- and Greek-born men and women ${ }^{(9)}$. The FFQ included twenty-seven items under the heading 'soups, salads and cooked vegetables', plus a separate question on garlic; nineteen under 'dried, fresh, stewed and canned fruits', plus two fruit juice items that constituted the 'vegetable (potatoes excluded)' and 'fruit (avocado and olives excluded)' groups, respectively. Carotenoids were also contributed by the items 'pasta/noodles', 'pizza', 'butter', 'margarine' and various 'mixed dishes' assumed to include vegetables. For each item on the FFQ there were nine response options ranging from never/less than once per month to $\geq 6$ times per day. The dietary questionnaire covered dietary supplements, including multivitamins, vitamin A and vitamin E. Supplement use was not quantified, so it was not possible to calculate nutrient intakes from these. Sex-specific average portion sizes were used in calculation of nutrient intakes from the 121 foods. Carotenoid composition of foods was based on US Department of Agriculture (USDA) data ${ }^{(15)}$, vitamin $\mathrm{E}$ was based on British data $^{(16)}$ and other nutrient composition data were derived from the Australian NUTTAB95 database ${ }^{(17)}$. Dietary antioxidant intakes are expressed as the total intake $(\mu \mathrm{g} / \mathrm{d})$ and per unit of daily energy intake $(\mu \mathrm{g} / \mathrm{MJ})^{(18)}$.

\section{Other measurements}

Participants underwent physical measurements, including weight and height, which were used to calculate BMI (kg/ $\mathrm{m}^{2}$ ). A structured interview schedule was used to obtain information on country of birth, smoking, alcohol consumption and history of common chronic illness, including angina, heart attack and diabetes.

\section{Reproducibility of diet and plasma antioxidant intake}

Reliability coefficients were calculated to assess the consistency of dietary and plasma antioxidant measures 
over time. The reliability coefficients for the plasma antioxidants were calculated from two blood samples collected from seventy-four subjects approximately twelve months apart. Each blood sample was split into two parts to allow estimation of within-laboratory variation. Components of variance models were used to identify the three sources of variability, i.e. between-subject, within-subject and withinlaboratory. The reliability coefficients for the dietary antioxidants were calculated from 242 subjects who were invited to complete a second FFQ twelve months after baseline. Selection was stratified by sex, country of birth (Australia, Italy, Greece), 10-year age group (40-49, 50-59, 60-69 years) and month of attendance. For both the plasma and dietary antioxidants, the reliability coefficient was the proportion of the total variance due to the between-subject component.

\section{Statistical analyses}

The mean and standard deviation are given for normally distributed data, while the median and the interquartile range are given for non-normally distributed data. Plasma antioxidant concentrations were excluded on days when the CV for the quality control samples was $>15 \%$, so the number of subjects included in the analyses differs for each antioxidant.

Dietary antioxidants were energy-adjusted using the nutrient density method, i.e. antioxidant intakes were divided by energy intakes. Similarly, plasma antioxidant levels were adjusted for plasma cholesterol by dividing antioxidant by cholesterol concentrations. Both plasma and dietary antioxidant concentrations were then natural log transformed after a constant of 1 was added to all observations to account for zero values. Pearson correlation coefficients were calculated to measure the association between adjusted plasma and dietary antioxidants. These correlation coefficients are likely to attenuate the association between the plasma and dietary antioxidants due to within-person variation in both measures. Therefore a corrected correlation coefficient was calculated for each antioxidant using the following formula:

$$
r_{\text {corr }}=\frac{r_{\text {crude }}}{\sqrt{R_{\mathrm{PL}} \times R_{\mathrm{FFQ}}}},
$$

where $r_{\text {corr }}$ is the corrected correlation coefficient; $r_{\text {crude }}$ is the observed crude correlation coefficient; $R_{\mathrm{PL}}$ is the reliability coefficient (intra-class correlation for the repeated measures) of the plasma antioxidants; and $R_{\mathrm{FFQ}}$ is the reliability coefficient of the dietary antioxidants. Confidence intervals were calculated for $r_{\text {corr }}$ using the formulae given by Rosner and Willett ${ }^{(19)}$. Associations between the dietary and plasma antioxidants were also assessed by calculating the weighted kappa statistic for quintile groupings.

To allow for between-batch variation in the plasma antioxidant assay, we also used within-batch quartile groups to rank antioxidant values against others from the same assay run. The association between plasma and dietary antioxidants was re-assessed using linear regression models with dietary antioxidant as the dependent variable and plasma antioxidant (defined using withinbatch quartile groups) as a pseudo-continuous variable.

Linear regression analyses were performed to identify potential effect modifiers. Interaction terms were included to examine which subject characteristics modified the association between dietary and plasma antioxidant concentrations. The significance level was set at $P \leq 0 \cdot 02$. The following variables were tested as potential effect modifiers: age, sex, country of birth (Australia $v$. UK $v$. Italy $v$. Greece), BMI category $\left(\mathrm{kg} / \mathrm{m}^{2}:<25,25-29 \cdot 9\right.$, $\geq 30$ ), smoking status (never, former, current), alcohol intake (sex-specific categories defined in Table 1), previous history of chronic disease, vitamin supplement use (vitamin A, vitamin C, vitamin E), fruit intake (0-1, 2-3, 4-5, $\geq 6$ servings/d) and vegetable intake $(0-2,3-4,5-6, \geq 7$ servings/d). Plasma antioxidants were modelled as the dependent variable and the corresponding dietary intakes as the independent variable. For interactions with $P<0 \cdot 02$, the median plasma biomarker concentration in each quintile of the corresponding dietary intake was plotted by stratum of the effect modifiers. We assumed that effect modification was not clinically important if the associations were in the same direction and the magnitude of the slope did not vary by more than $50 \%$ across strata.

A list of potentially important foods was selected based on each food's contribution to total dietary antioxidants. This was determined through a forward inclusion (stepwise) regression procedure ( $P$ for removal $=0 \cdot 12, P$ for entry $=0 \cdot 02$ ). The associations between each of the foods selected above and the plasma antioxidant concentrations were then investigated using multiple linear regression models.

The association between plasma carotenoid concentrations (dependent variable) and total fruit or vegetable intake as categorical variable was investigated using multiple linear models adjusting for energy intake, BMI, smoking status, gender, age and country of birth. To investigate if there was a linear association between plasma carotenoid concentrations and total fruit or vegetable intake, we compared the regression models with total fruit or vegetable intake as categorical variables $v$. total fruit or vegetable intake as pseudo-continuous variables using the likelihood ratio test.

All statistical analyses were performed using the Stata/ SE $8 \cdot 2$ statistical software package (Stata Corporation, College Station, TX, USA).

\section{Results}

Demographic and clinical characteristics of the 3110 participants, by gender, are presented in Table 1 . Because of the loss of male samples, men comprised just over $35 \%$ of the sample compared with $41 \%$ in the whole cohort. About $22 \%$ of the study participants were born in Greece or Italy, 
Table 1 Characteristics of study participants: sub-cohort of randomly selected men and women from the Melbourne Collaborative Cohort Study (MCCS)

\begin{tabular}{|c|c|c|c|c|}
\hline \multirow[b]{2}{*}{ Characteristic } & \multicolumn{2}{|c|}{ Men $(n 1086,35 \cdot 1 \%)$} & \multicolumn{2}{|c|}{ Women (n 2024, 64.9\%) } \\
\hline & $n$, Mean or Median & $\%$, SD or IQR & $n$, Mean or Median & $\%$, sD or IQR \\
\hline \multicolumn{5}{|l|}{ Country of birth* } \\
\hline Australia & 701 & $64 \cdot 6$ & 1474 & $72 \cdot 8$ \\
\hline UK & 81 & $7 \cdot 5$ & 155 & $7 \cdot 7$ \\
\hline Italy & 161 & $14 \cdot 8$ & 231 & $11 \cdot 4$ \\
\hline Greece & 143 & $13 \cdot 2$ & 164 & $8 \cdot 1$ \\
\hline Age (years)† & $55 \cdot 3$ & $8 \cdot 5$ & $54 \cdot 5$ & $8 \cdot 5$ \\
\hline BMI $\left(\mathrm{kg} / \mathrm{m}^{2}\right) \dagger$ & $27 \cdot 2$ & 3.5 & $26 \cdot 6$ & $5 \cdot 1$ \\
\hline Energy intake $(\mathrm{kJ} / \mathrm{d}) \ddagger$ & 9686 & $7915-11980$ & 8107 & $6479-10073$ \\
\hline Plasma cholesterol $(\mathrm{mmol} / \mathrm{l}) \ddagger$ & $5 \cdot 43$ & $4 \cdot 80-6 \cdot 11$ & $5 \cdot 50$ & $4 \cdot 82-6 \cdot 20$ \\
\hline \multicolumn{5}{|l|}{ Smoking status* } \\
\hline Never & 428 & $39 \cdot 4$ & 1400 & $69 \cdot 2$ \\
\hline Current & 167 & $15 \cdot 4$ & 173 & $8 \cdot 6$ \\
\hline Former & 491 & $45 \cdot 2$ & 451 & $22 \cdot 3$ \\
\hline \multicolumn{5}{|l|}{ Alcohol intake* } \\
\hline None & 195 & $18 \cdot 0$ & 829 & $41 \cdot 0$ \\
\hline $1-39 \mathrm{~g} / \mathrm{d} \mathrm{M} ; 1-19 \mathrm{~g} / \mathrm{d} \mathrm{F}$ & 715 & $65 \cdot 9$ & 960 & $47 \cdot 5$ \\
\hline $40-59 \mathrm{~g} / \mathrm{d} \mathrm{M} ; 20-39 \mathrm{~g} / \mathrm{d} \mathrm{F}$ & 97 & 8.9 & 186 & $9 \cdot 2$ \\
\hline$\geq 60 \mathrm{~g} / \mathrm{d} \mathrm{M} ; \geq 40 \mathrm{~g} / \mathrm{d} \mathrm{F}$ & 78 & $7 \cdot 2$ & 48 & $2 \cdot 4$ \\
\hline Baseline illnesses§ & 135 & $12 \cdot 4$ & 122 & $6 \cdot 0$ \\
\hline \multicolumn{5}{|l|}{ Vitamin supplement use* } \\
\hline Vitamin A & 18 & $1 \cdot 7$ & 77 & $3 \cdot 8$ \\
\hline Vitamin C & 130 & $12 \cdot 0$ & 382 & $18 \cdot 9$ \\
\hline Vitamin E & 67 & $6 \cdot 2$ & 192 & $9 \cdot 5$ \\
\hline
\end{tabular}

M, males; F, females.

${ }^{*} n$ and $\%$.

tMean and SD.

$\ddagger$ Median and interquartile range (IQR).

$\S$ Self-reported heart attack, angina or diabetes.

similar to proportions in the whole cohort (24\%). The average age of the participants was $54 \cdot 8$ (sD $8 \cdot 6$ ) years.

Dietary and plasma antioxidant concentrations for men and women are presented in Table 2. The median adjusted values for dietary intake and plasma carotenoid concentrations were consistently higher for women than men. The adjusted dietary intakes of retinol and vitamin $\mathrm{E}$ were also higher for women; however, the plasma levels of retinol and tocopherols were higher for men.

Table 3 gives the crude, adjusted and corrected correlation coefficients for the association between dietary antioxidants and their plasma biomarkers. It also lists reliability coefficients for dietary and plasma antioxidant concentrations. Men and women have been combined, as there was no evidence that the associations were modified by sex. Adjustment for age, alcohol intake, BMI, country of birth, laboratory, history of chronic illness, gender and smoking made little difference to the correlation coefficients (data not shown).

Correlation coefficients for the carotenoids ranged from $0 \cdot 28$ for lycopene to $0 \cdot 46$ for $\beta$-cryptoxanthin. There was no association between dietary and plasma retinol. The weighted $\kappa$ statistic for quintile groupings ranged from $0 \cdot 25$ for lycopene to $0 \cdot 42$ for $\beta$-cryptoxanthin, and was only $0 \cdot 032$ for retinol.

The reliability coefficients for dietary and plasma lycopene, and dietary $\beta$-cryptoxanthin were low, inflating the corrected correlations to give values of $r>1$. The corrected correlations for lutein/zeaxanthin and $\alpha$-carotene were quite strong, while a moderate corrected correlation was observed for $\beta$-carotene. No correlation was seen for retinol. Correlations between dietary vitamin $\mathrm{E}$ and plasma concentrations of $\alpha$ - and $\boldsymbol{\gamma}$-tocopherol were very weak, $0 \cdot 07(95 \% \mathrm{CI} 0 \cdot 04,0 \cdot 11)$ and -0.07 (95\% CI $-0.04,0 \cdot 03)$, respectively, and were strengthened by correction for intra-individual variation to $0 \cdot 20$ and $-0 \cdot 02$, respectively. Reliability coefficients for dietary vitamin $\mathrm{E}$ and plasma $\alpha$-tocopherol were 0.33 and 0.36 , respectively. Reliability was not calculated for plasma $\gamma$-tocopherol due to the large number of values below the limits of detection. Similar associations were found when plasma antioxidants were modelled as within-batch quartile groups.

Potential effect modifiers $(P$ value $<0 \cdot 02)$ of the association between diet and plasma $\alpha$-carotene were assessed visually (see Fig. 1). Within strata of age or BMI, associations were all positive; the magnitude of changes in plasma concentrations per unit increment in dietary intake was reduced by about $30 \%$ in older groups compared with those $<50$ years, and by less than $50 \%$ for increasing BMI groups. Statistically significant interactions between plasma tocopherols and vitamin $\mathrm{E}$ intakes were not explored further owing to the lack of correlation between these overall. 
Table 2 Dietary and plasma carotenoids, retinol and vitamin E among a sub-cohort of randomly selected men and women from the Melbourne Collaborative Cohort Study (MCCS)

\begin{tabular}{|c|c|c|c|c|c|c|c|c|c|c|c|c|c|c|c|c|}
\hline & \multicolumn{8}{|c|}{ Unadjusted values } & \multicolumn{8}{|c|}{ Adjusted values } \\
\hline & \multicolumn{4}{|c|}{ FFQ ( $\mu \mathrm{g} / \mathrm{d})$} & \multicolumn{4}{|c|}{ Plasma $(\mu \mathrm{mol} / \mathrm{l})$} & \multicolumn{4}{|c|}{ FFQ $(\mu \mathrm{g} / \mathrm{MJ})^{*}$} & \multicolumn{4}{|c|}{ Plasma $(\mu \mathrm{mol} / \mathrm{mol}) \dagger$} \\
\hline & \multicolumn{2}{|r|}{ Men } & \multicolumn{2}{|c|}{ Women } & \multicolumn{2}{|c|}{ Men } & \multicolumn{2}{|c|}{ Women } & \multicolumn{2}{|r|}{ Men } & \multicolumn{2}{|c|}{ Women } & \multicolumn{2}{|r|}{ Men } & \multicolumn{2}{|c|}{ Women } \\
\hline & Median & IQR & Median & IQR & Median & IQR & Median & IQR & Median & IQR & Median & IQR & Median & IQR & Median & IQR \\
\hline \multicolumn{17}{|l|}{ Carotenoids } \\
\hline$\alpha$-Carotene & 1245 & $558-1618$ & 1130 & 654-1799 & 0.08 & $0.04-0.13$ & $0 \cdot 11$ & $0 \cdot 07-0 \cdot 17$ & 113 & $63 \cdot 0-171$ & 139 & $85 \cdot 7-205$ & $14 \cdot 0$ & $8 \cdot 0-23 \cdot 7$ & $20 \cdot 5$ & $12 \cdot 5-32 \cdot 1$ \\
\hline$\beta$-Carotene & 5143 & $3315-7028$ & 5266 & $3866-7125$ & $0 \cdot 48$ & $0 \cdot 28-0.77$ & $0 \cdot 71$ & $0.47-1.06$ & 510 & $359-670$ & 645 & $471-844$ & $86 \cdot 4$ & $52 \cdot 4-143$ & $128 \cdot 0$ & $87 \cdot 0-193$ \\
\hline$\beta$-Cryptoxanthin & 324 & $160-588$ & 349 & $180-592$ & $0 \cdot 16$ & $0.09-0.31$ & $0 \cdot 27$ & $0.15-0.45$ & $33 \cdot 2$ & $18 \cdot 1-58 \cdot 4$ & $43 \cdot 1$ & $23 \cdot 5-70 \cdot 3$ & $29 \cdot 6$ & $16 \cdot 2-55 \cdot 9$ & $48 \cdot 2$ & $26 \cdot 4-82 \cdot 4$ \\
\hline Lycopene & 7108 & $4067-10513$ & 6264 & $3995-9446$ & 0.50 & $0 \cdot 32-075$ & 0.51 & $0.35-0.72$ & 740 & $430-1087$ & 761 & $505-1159$ & $92 \cdot 6$ & $58 \cdot 9-138$ & $94 \cdot \overline{7}$ & $61 \cdot 8-134$ \\
\hline Lutein/zeaxanthin & 1615 & $1064-2282$ & 1697 & $1193-2304$ & 0.30 & $0.21-0.43$ & 0.33 & $0.23-0.47$ & 163 & $113-235$ & 205 & $148-282$ & $55 \cdot 1$ & $38 \cdot 0-80 \cdot 0$ & $61 \cdot 0$ & $42 \cdot 3-86 \cdot 8$ \\
\hline Retinol & 505 & $309-826$ & 531 & $322-961$ & $2 \cdot 47$ & $2 \cdot 06-2 \cdot 87$ & $2 \cdot 18$ & $1 \cdot 81-2 \cdot 53$ & $53 \cdot 1$ & $36.6-76 \cdot 0$ & $66 \cdot 8$ & $46 \cdot 1-112$ & $458 \cdot 0$ & $378-540$ & $390 \cdot 0$ & $328-468$ \\
\hline \multicolumn{17}{|l|}{ Tocopherols } \\
\hline $\begin{array}{l}\text { Vitamin E } \\
\alpha \text {-Tocopherol }\end{array}$ & $\begin{array}{c}7840 \\
-\end{array}$ & $\begin{array}{c}5890-10320 \\
-\end{array}$ & $\begin{array}{c}7370 \\
-\end{array}$ & $\begin{array}{c}5700-9530 \\
-\end{array}$ & $\overline{33.87}$ & $28 \cdot{ }^{-}-41 \cdot 1$ & $\overline{34 \cdot 0}$ & $28 \cdot 8-40 \cdot 4$ & 803 & $\begin{array}{l}670-970 \\
-\end{array}$ & $\begin{array}{r}914 \\
-\end{array}$ & $\begin{array}{c}760-1090 \\
-\end{array}$ & $6240 \cdot 0$ & $\begin{array}{c}- \\
5360-7380\end{array}$ & $6140 \cdot 0$ & $\begin{array}{c}- \\
5450-7020\end{array}$ \\
\hline $\begin{array}{l}\alpha \text {-Tocopherol } \\
\gamma \text {-Tocopherol }\end{array}$ & - & - & - & - & 1.63 & $1 \cdot 17-2 \cdot 33$ & $\begin{array}{r}34 \cdot 0 \\
1.48\end{array}$ & $\begin{array}{l}28 \cdot 8-40 \cdot 4 \\
1 \cdot 05-2 \cdot 03\end{array}$ & - & - & - & $\begin{array}{l}- \\
-\end{array}$ & $302 \cdot 0$ & $215-419$ & $\begin{array}{r}6140 \cdot 0 \\
266 \cdot 0\end{array}$ & $\begin{array}{c}5450-1020 \\
197-367\end{array}$ \\
\hline
\end{tabular}

IQR, interquartile range.

(FFQ; $\mu \mathrm{g} / \mathrm{d})$ was adjusted for daily energy intake (MJ/d).

tPlasma antioxidant levels $(\mu \mathrm{mol} / \mathrm{l})$ were adjusted for plasma cholesterol concentration (mol/l).

Table 3 Correlation coefficients for the associations between dietary carotenoids, retinol and their plasma biomarkers among a sub-cohort of randomly selected men and women from the Melbourne Collaborative Cohort Study (MCCS)

\begin{tabular}{|c|c|c|c|c|c|c|c|c|c|c|}
\hline & \multicolumn{2}{|c|}{$\begin{array}{l}\text { Crude correlation } \\
\text { coefficient }^{*}\end{array}$} & \multicolumn{2}{|c|}{$\begin{array}{l}\text { Adjusted correlation } \\
\text { coefficientt }\end{array}$} & \multicolumn{2}{|c|}{$\begin{array}{l}\text { Corrected correlation } \\
\text { coefficient } \neq\end{array}$} & \multicolumn{2}{|c|}{$\begin{array}{l}\text { Reliability coefficient for } \\
\text { FFQ }(n \text { 242) }\end{array}$} & \multicolumn{2}{|c|}{$\begin{array}{l}\text { Reliability coefficient for } \\
\text { plasma }(n 74) \S\end{array}$} \\
\hline & $r_{\text {crude }}$ & $95 \% \mathrm{Cl}$ & $r_{\mathrm{adj}}$ & $95 \% \mathrm{Cl}$ & $r_{\text {corr }}$ & $95 \% \mathrm{Cl}$ & $R_{\mathrm{FFQ}}$ & $95 \% \mathrm{Cl}$ & $R_{\mathrm{PL}}$ & $95 \% \mathrm{Cl}$ \\
\hline \multicolumn{11}{|l|}{ Carotenoids } \\
\hline$\alpha$-Carotene $(n$ 2744) $\|$ & 0.35 & $0.31,0.38$ & 0.40 & $0.37,0.43$ & 0.78 & $0.68,0.85$ & 0.57 & $0.49,0.66$ & $0 \cdot 46^{\star \star}$ & $0.31,0.59$ \\
\hline$\beta$-Carotene (n 2876) & 0.23 & $0 \cdot 19,0.26$ & 0.28 & $0.24,0.31$ & 0.57 & $0.43,0.69$ & 0.49 & $0.40,0.59$ & 0.49 & $0.31,0.57$ \\
\hline$\beta$-Cryptoxanthin (n 2975) & 0.40 & $0.36,0.43$ & 0.46 & $0.43,0.49$ & 1.0 & - & $0 \cdot 13$ & $0.01,0.26$ & 0.48 & $0.36,0.57$ \\
\hline Lycopene ( $n$ 2679) & 0.21 & $0 \cdot 18,0 \cdot 25$ & 0.28 & $0.24,0.31$ & 1.0 & - & 0.30 & $0.19,0.41$ & 0.25 & $0.02,0.39$ \\
\hline Lutein/zeaxanthin ( $n$ 2990) & $0 \cdot 21$ & $0 \cdot 18,0.25$ & 0.29 & $0.26,0.32$ & 0.73 & $0.49,0.87$ & $0 \cdot 34$ & $0.23,0.45$ & $0 \cdot 47$ & $0.33,0.57$ \\
\hline Retinol ( $n$ 3084) & 0.027 & $-0.01,0.06$ & 0.037 & $0.02,0.08$ & 0.08 & $0.002,0.16$ & 0.37 & $0.26,0.48$ & 0.52 & $0.38,0.66$ \\
\hline
\end{tabular}

*Pearson's correlation coefficients were obtained using log-transformed dietary intake and log-transformed plasma biomarker levels

tPearson's correlation coefficients were obtained using log-transformed dietary intake that had been corrected for total energy intake and log-transformed plasma biomarker levels that had been adjusted for plasma tPearson's correlation coefficients were obtained using log-transformed dietary intake that had been corrected for total energy intake and log-transformed plasma biomarker levels that had been adjusted for plasma
cholesterol levels. tCorrected for the

concentration ine relia

concentration in plasma.

inumber of subjects.

-Truncated at the value of 1 .

${ }^{*}$ Calculated from data of sixty-five subjects. 

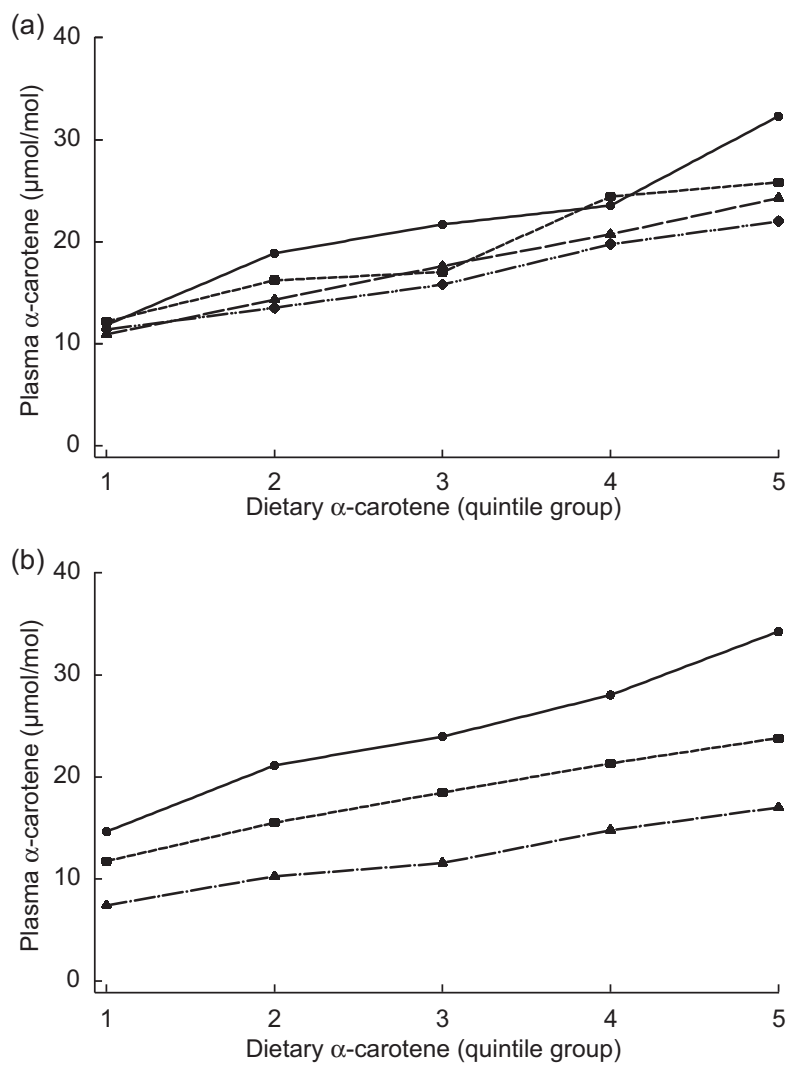

Figure 1 Median plasma antioxidant concentrations by quintiles of dietary intake, stratified by putative effect modifiers identified in multiple regression analyses, in a sub-cohort of randomly selected men and women from the Melbourne Collaborative Cohort Study (MCCS). (a) $\alpha$-Carotene stratified by age: $-\bullet-,<50$ years; - - - - - 50-54.9 years; $-\mathbf{\Delta}-\longrightarrow, 55-64.9$ years; $-\cdots-\bullet-\cdots-,>65$ years. (b) $\alpha$-Carotene stratified by BMI: $-\bullet-,<25 \mathrm{~kg} / \mathrm{m}^{2}$; $-\mathbf{\square}--, 25-29.9 \mathrm{~kg} / \mathrm{m}^{2} ;-\cdot-\boldsymbol{\Delta}-\cdot-, \geq 30 \mathrm{~kg} / \mathrm{m}^{2}$

\section{Association between individual foods, fruit and vegetables, and plasma antioxidant concentrations}

Carrot intake was the main dietary predictor of plasma $\alpha$ - and $\beta$-carotene concentrations. The consumption of oranges and mandarins was the main predictor of plasma $\beta$-cryptoxanthin concentration. No single individual food stood out as a strong predictor of plasma lutein/zeaxanthin. Pasta dishes were the main dietary predictor of plasma lycopene (Table 4). No foods were associated with plasma retinol concentration. The use of vitamin $\mathrm{E}$ supplements was a predictor of plasma $\alpha$-tocopherol. For $\gamma$-tocopherol the strongest association was an inverse association with vitamin E supplements (data not shown).

Mean plasma concentrations of carotenoids increased across fruit and vegetable intake groups (Table 5). The associations were linear and significant for $\alpha$-carotene, $\beta$-carotene, lycopene, lutein/zeaxanthin and vegetable intake, and for $\alpha$-carotene and fruit intake. Linear associations were not observed for $\beta$-carotene and fruit intake
( $P=0.04$ for likelihood ratio test of linear association), $\beta$-cryptoxanthin and both vegetable and fruit intake $(P=0.03$ and $P<0 \cdot 001$, respectively, for likelihood ratio tests of linear association), and lutein/zeaxanthin and fruit intake $(P=0.03$ for likelihood ratio test of linear association). There was weak statistical evidence for a dose-response association between lycopene and fruit intake $(P=0 \cdot 06)$. While the associations of $\beta$-cryptoxanthin with fruit and vegetable intakes were non-linear, there were incremental increases in plasma levels across fruit and vegetable intake categories, and the levels in the top intake group were more than twice those in the bottom intake group.

\section{Discussion}

We observed significant but modest correlations between dietary and plasma carotenoids, which were strengthened by adjustment for variation in both sets of measures. However, for lycopene and $\beta$-cryptoxanthin, the reliability coefficients were so low that adjusting for intra-individual variation resulted in correlation coefficients greater than one. No important effect modifiers of these associations were identified, although plasma $\beta$-cryptoxanthin concentrations were lower in smokers than non-smokers for all levels of dietary intake. There was no evidence of an association between diet and plasma levels of retinol or between vitamin $\mathrm{E}$ and $\alpha$ - and $\gamma$-tocopherols. Carrots were the single food most strongly associated with variations in plasma $\alpha$ - and $\beta$-carotene, oranges and mandarins with $\beta$-cryptoxanthin and pasta dishes with lycopene. Lutein/ zeaxanthin did not show any close association with a single food item. Individual plasma carotenoid concentrations were associated with intakes of total fruit and vegetables.

As an evaluation of an FFQ designed to measure intake over the previous 12 months, the present study is limited by the use of a single blood sample as the comparison measure. Hunter ${ }^{(14)}$ notes that plasma $\beta$-carotene integrates intake over several weeks, and plasma carotenoid levels responded to dietary changes within a few weeks ${ }^{(20)}$, thus these are not long-term markers of intake ${ }^{(21)}$. However, a single measurement was sufficient to rank serum levels of $\alpha$ - and $\beta$-carotene and lutein/ zeaxanthin according to long-term intake ${ }^{(22)}$. This is consistent with the reliabilities we observed for these carotenoids. We also found that the reliability of plasma $\beta$-cryptoxanthin was reasonably high, although the reliability for dietary intake was low.

Biomarkers of intake are recognized as useful measures against which to evaluate dietary instruments, owing to the independence of errors in these two methods ${ }^{(23)}$. However, plasma retinol concentration is closely regulated homeostatically via retinol-binding protein over most of the intake range ${ }^{(14)}$; thus the lack of an association is not necessarily a reflection of poor measurement of 
Table 4 Association between individual foods and plasma carotenoid concentrations among a sub-cohort of randomly selected men and women from the Melbourne Collaborative Cohort Study (MCCS)

\begin{tabular}{|c|c|c|c|c|}
\hline Plasma carotenoid & Individual food & Partial correlation coefficient ${ }^{*}$ & $P$ value & Model $R^{2}$ \\
\hline$\alpha$-Carotene & $\begin{array}{l}\text { Carrot } \\
\text { Soups } \\
\text { Orange/mandarin } \\
\text { Broccoli } \\
\text { Sweet corn } \\
\text { Use multivitamins (yes/no) }\end{array}$ & $\begin{array}{l}0.281 \\
0.088 \\
0.076 \\
0.093 \\
0.054 \\
0.051\end{array}$ & $\begin{array}{r}<0.001 \\
<0.001 \\
<0.001 \\
<0.001 \\
0.005 \\
0.007\end{array}$ & 0.358 \\
\hline$\beta$-Carotene & $\begin{array}{l}\text { Carrot } \\
\text { Pumpkin } \\
\text { Soups } \\
\text { Cantaloupe/honeydew } \\
\text { Vitamin A }\end{array}$ & $\begin{array}{l}0 \cdot 129 \\
0 \cdot 054 \\
0.072 \\
0 \cdot 044 \\
0 \cdot 076\end{array}$ & $\begin{array}{r}<0.001 \\
0.004 \\
<0.001 \\
0.020 \\
<0.001\end{array}$ & $0 \cdot 229$ \\
\hline$\beta$-Cryptoxanthin & $\begin{array}{l}\text { Orange/mandarin } \\
\text { Orange/lemon juice } \\
\text { Broccoli } \\
\text { Peaches/nectarines } \\
\text { Avocado }\end{array}$ & $\begin{array}{l}0 \cdot 318 \\
0 \cdot 101 \\
0 \cdot 076 \\
0.075 \\
0.043\end{array}$ & $\begin{array}{r}<0.001 \\
<0.001 \\
<0.001 \\
<0.001 \\
0.020\end{array}$ & $0 \cdot 284$ \\
\hline Lutein/zeaxanthin & $\begin{array}{l}\text { Green leafy vegetables (silverbeet, spinach) } \\
\text { Salad greens (lettuce, endive) } \\
\text { Broccoli } \\
\text { Orange/mandarin } \\
\text { Onions/leeks } \\
\text { Avocado }\end{array}$ & $\begin{array}{l}0.044 \\
0.068 \\
0.072 \\
0.054 \\
0.058 \\
0.052\end{array}$ & $\begin{array}{r}0.017 \\
<0.001 \\
<0.001 \\
0.003 \\
0.001 \\
0.004\end{array}$ & $0 \cdot 207$ \\
\hline Lycopene & $\begin{array}{l}\text { Pasta dishes } \\
\text { Pizza } \\
\text { Tomato } \\
\text { Legume soup }\end{array}$ & $\begin{array}{l}0.113 \\
0.061 \\
0.082 \\
0.049\end{array}$ & $\begin{array}{r}<0.001 \\
0.002 \\
<0.001 \\
0.011\end{array}$ & $0 \cdot 138$ \\
\hline
\end{tabular}

*Partial correlation coefficient adjusted for each of the foods listed above and age, sex, BMI, country of birth, smoking, vitamin A, C, E and multivitamin supplements.

intake. Carotenoids are not similarly homeostatically regulated, and the only source of these in plasma is diet, but there are a number of other factors that can influence plasma levels such as age, sex, smoking, BMI and alcohol consumption ${ }^{(14,24)}$.

Using plasma antioxidants as biomarkers of intake does not allow assessment of the precision of absolute intake estimates, but as dietary variables are typically analysed as quartile or quintile groupings, the ranking of participants by intake is the most important quality of the FFQ.

Strengths of the present study include the large number of participants and the comprehensive information available for potential modifiers of the associations between plasma and dietary antioxidants. Limitations include the small sample sizes for the reliability studies of the FFQ and plasma antioxidants, and the possibility that the reliability coefficients for dietary antioxidant intake may be biased due to systematic error.

Other studies that have looked at the correlations between dietary intake of carotenoids using the Mangels ${ }^{(25)}$ or USDA database and plasma/serum concentrations have observed varying degrees of association. Correlations from different studies are not directly comparable as different adjustments were used, often including age, sex, BMI, alcohol intake, smoking or excluding smokers, as well as energy intake and some measure of blood lipids $^{(6,21,26-30)}$. Adjusted correlations ranged from $0 \cdot 24$ to 0.56 for $\alpha$-carotene ${ }^{(30,31)}$, from 0.13 to 0.51 for $\beta$-carotene $^{(29,30)}$, from -0.002 to 0.55 for $\beta$-cryptoxanthin ${ }^{(27,30)}$, from 0.03 to 0.42 for lutein/zeaxanthin ${ }^{(27,31)}$ and from $0 \cdot 13$ to $0 \cdot 47$ for lycopene ${ }^{(6,31)}$. The two extremely low correlation coefficients were observed in an Australian study with only twenty-eight subjects ${ }^{(27)}$. None of these studies used a correction for intra-individual variation in dietary or plasma carotenoids; hence their results should be compared with our correlations adjusting for dietary energy and plasma cholesterol. The correlations observed in the MCCS fall within the range of previously observed values.

It does not appear from these studies that any particular carotenoid is consistently measured better or worse than others. Different dietary questionnaires may vary in their completeness for inclusion of carotenoid-containing foods, and the bioavailability of carotenoids may vary depending on the overall diet and methods of preparation of carotenoid-rich foods ${ }^{(32)}$. Lycopene bioavailability is strongly influenced by food preparation and co-ingestion of fat, and exhibits very wide inter-individual variability ${ }^{(33,34)}$.

Two US studies have looked at specific foods related to intake $^{(26)}$ and plasma concentrations ${ }^{(35)}$ of individual carotenoids. In these studies, carrots were associated with $\alpha$ - and $\beta$-carotene, oranges and orange juice with $\beta$-cryptoxanthin, tomatoes and tomato products with lycopene and green leafy vegetables with lutein/zeaxanthin, consistent with our results. Lutein/zeaxanthin had a variety of sources and was less closely associated with a single food item/group than the other carotenoids. In some 3000 participants of the European Prospective 
Investigation into Cancer and Nutrition from across Europe, associations between plasma carotenoids and fruit and vegetables and subgroups of these were evaluated ${ }^{(36)}$. Total fruit intake was the strongest predictor of $\beta$-cryptoxanthin, fruit other than citrus for lutein, fruit and vegetables for zeaxanthin, tomato products for lycopene, carrots for $\alpha$-carotene; and for $\beta$-carotene no single item was a good predictor, consistent with its many dietary sources in this population ${ }^{(36)}$. Differences between European and US studies may to some degree reflect different dietary patterns. A recent Australian study evaluated plasma carotenoids against intakes of total fruit and vegetables and found strong associations for each carotenoid except lycopene with both fruit and vegetable intake, adjusting for a wide range of potential confounders ${ }^{(37)}$. This is generally consistent with our findings.

The lack of association between diet and plasma retinol concentrations is consistent with other studies cited by Kaaks et al. ${ }^{(23)}$ and Hunter ${ }^{(14)}$. Serum or plasma retinol concentration only reflects intake at the extremes of intake, otherwise it is homeostatically controlled and remains reasonably constant ${ }^{(14,38)}$, as reflected in the relatively high reliability observed for plasma retinol.

We observed no association between dietary vitamin $\mathrm{E}$ intake ( $\alpha$-tocopherol equivalents) and plasma concentrations of either $\alpha$ - or $\gamma$-tocopherol. This is in contrast to Willett et $a l^{(39)}$, who found a correlation between dietary vitamin E (without supplements) and plasma $\alpha$-tocopherol of 0.34 after adjusting for energy intake, plasma lipids, age and sex. Elsewhere, it has been noted that correlations between $\alpha$-tocopherol intake and plasma levels are largely attributable to intake from dietary supplements ${ }^{(40)}$, consistent with our observation that plasma $\alpha$-tocopherol was most strongly associated with use of vitamin E supplements (typically $\alpha$-tocopherol acetate). Several other studies have also reported no association between diet and plasma levels of $\alpha$-tocopherol ${ }^{(41,42)}$ and it has been suggested that there is a stronger correlation between dietary and plasma $\gamma$-tocopherol than for $\alpha$-tocopherol ${ }^{(40)}$, but we were not able to differentiate between $\alpha$ - and $\gamma$-tocopherol in diet.

In conclusion, the correlations we observed between plasma and dietary carotenoids were within the ranges observed in previous studies; however, due to poor reliability for the intake of $\beta$-cryptoxanthin, and for both intake and plasma lycopene, we are less confident of our ability to measure intakes of these carotenoids. More sophisticated assessment of dietary patterns, food preparation and seasonal variation in intake of specific foods may be required to better determine the relationships of intake to circulating levels. Tissue-specific uptake of carotenoids such as lutein and lycopene may also influence circulating levels. Plasma levels of retinol and tocopherols do not appear to be useful as biomarkers of intake in most studies, and we observed no associations with intake. Plasma levels of carotenoids also show strong 
associations with intake of fruit and vegetables, suggesting that these are reasonably measured by the FFQ.

\section{Acknowledgements}

This work was funded by VicHealth, The Cancer Council Victoria and the National Health and Medical Research Council (grant ID 124317, 126402, 126403, 180705, 180706, 194327, 209057 and 251533). None of the authors has any conflict of interest. A.M.H. planned the analysis and wrote the manuscript. J.A.S. assisted with the analysis plan, supervised the analysis and commented on the manuscript. M.F. performed the statistical analysis. K.G.R. advised on the analysis plan and commented on the manuscript. D.R.E. advised on the analysis plan and commented on the manuscript. K.O.D. commented on the manuscript and was involved in the establishment of the Melbourne Collaborative Cohort Study. S.Q. developed the carotenoid method and performed assays at Monash. G.G.G. was responsible for the establishment of the Melbourne Collaborative Cohort Study and commented on the manuscript. This study was made possible by the contribution of many people, including the original investigators and the diligent team who recruited the participants and who continue working on follow-up. We would like to express our gratitude to the many thousands of Melbourne residents who continue to participate in the study. We would particularly like to acknowledge Michael Daskalakis for technical assistance in the analysis of the plasma antioxidants.

\section{References}

1. Baghurst K \& Binns C (2003) Food for Health. Dietary Guidelines for Australian Adults. A Guide to Healthy Eating. Canberra: Commonwealth Department of Health and Ageing/National Health and Medical Research Council.

2. Srinath Reddy K \& Katan MB (2004) Diet, nutrition and the prevention of hypertension and cardiovascular diseases. Public Health Nutr 7, 167-186.

3. Willett WC (2005) Diet and cancer: an evolving picture. JAMA 293, 233-234.

4. Ford E \& Mokdad AH (2001) Fruit and vegetable consumption and diabetes mellitus incidence among US adults. Prev Med 32, 33-39.

5. Montonen J, Jarvinen R, Heliovaara $M$, Reunanen A, Aromaa A \& Knekt P (2005) Food consumption and the incidence of type II diabetes mellitus. Eur J Clin Nutr 59, 441-448.

6. Michaud DS, Giovannucci EL, Ascherio A, Rimm EB, Forman MR, Sampson L \& Willett WC (1998) Associations of plasma carotenoid concentrations and dietary intake of specific carotenoids in samples of two prospective cohort studies using a new carotenoid database. Cancer Epidemiol Biomarkers Prev 7, 283-290.

7. Heaney RP (2006) Nutrition, chronic disease, and the problem of proof. Am J Clin Nutr 84, 471-472.

8. Schatzkin A \& Kipnis V (2004) Could exposure assessment problems give us wrong answers to nutrition and cancer questions? J Natl Cancer Inst 96, 1564-1565.
9. Ireland P, Jolley D, Giles G, O’Dea K, Powles J, Rutishauser I, Wahlqvist ML \& Williams J (1994) Development of the Melbourne FFQ: a food frequency questionnaire for use in an Australian prospective study involving an ethnically diverse cohort. Asia Pac J Clin Nutr 3, 19-31.

10. MacInnis RJ \& English DR (2004) Making the most of cohort studies: choosing between case-cohort and nested casecontrol designs. Aust Epidemiol 11, 26-29.

11. Thomas J, Kline M, Schiller S, Ellerbe P, Sniegoski L, Duewer D \& Sharpless KE (1996) Certification of fat soluble vitamins, carotenoids, and cholesterol in human serum: Standard Reference Material 968b. Anal Bioanal Chem 356, 1-9.

12. Su Q, Rowley KG \& O'Dea K (1999) Stability of individual carotenoids, retinol and tocopherols in human plasma during exposure to light and after extraction. J Chromatogr B 729, 191-198.

13. Su Q, Balazs ND, Daskalakis M \& Rowley KG (2003) Improved quantification of retinol, tocopherol and carotenoid in human plasma by HPLC using retinol acetate as internal standard. Asia Pac J Clin Nutr 12, Suppl., S63.

14. Hunter D (1998) Biochemical indicators of dietary intake. In Nutritional Epidemiology, 2nd ed., pp. 174-243 [WC Willett, editor]. New York: Oxford University Press.

15. US Department of Agriculture, Agricultural Research Service, Nutrient Data Laboratory (2003) USDA-NCC Carotenoid Database for US Foods - 1998. http://www.nal.usda.gov/ fnic/foodcomp/Data/car98/car98.html (accessed March 2009).

16. Holland B, Welch AA, Unwin ID, Buss DH, Paul AA \& Southgate DAT (1993) McCance and Widdowson's The Composition of Foods, 5th ed. Cambridge: Royal Society of Chemistry.

17. Lewis J, Milligan G \& Hunt A (1995) NUTTAB95 Nutrient Data Table for Use in Australia. Canberra: Australian Government Publishing Service.

18. Willett WC (editor) (1998) Nutritional Epidemiology, 2nd ed. New York: Oxford University Press.

19. Rosner B \& Willett WC (1998) Interval estimates for correlation coefficients corrected for within-person variation: implications for study design and hypothesis testing. Am J Epidemiol 127, 377-386.

20. Yeum K, Booth S, Sadowski J, Liu C, Tang G, Krinsky N \& Russell RM (1996) Human plasma carotenoid response to the ingestion of controlled diets high in fruits and vegetables. Am J Clin Nutr 64, 594-602.

21. Enger SM, Longnecker MP, Shikany JM, Swenseid ME, Chen MJ, Harper JM \& Haile RW (1995) Questionnaire assessment of intake of specific carotenoids. Cancer Epidemiol Biomarkers Prev 4, 201-205.

22. van Kappel AL, Steghens J-P, Zeleniuch-Jacqotte A, Chajés V, Toniolo P \& Riboli E (2001) Serum carotenoids as biomarkers of fruit and vegetable consumption in the New York Women's Health Study. Public Health Nutr 4, 829-835.

23. Kaaks R, Riboli E \& Sinha R (1997) Biochemical markers of dietary intake. In Applications of Biomarkers in Cancer Epidemiology, pp. 103-126 [P Toniolo, P Boffetta, DEG Shuker, N Rothman, B Hulka and N Pearce, editors]. Lyon: International Agency for Research on Cancer.

24. Brady WE, Mares-Perlman JA, Bowen P \& StacewiczSapuntzakis M (1996) Human serum carotenoid concentrations are related to physiologic and lifestyle factors. $J$ Nutr 126, 129-137.

25. Mangels AR, Holden JM, Beecher GR, Forman MR \& Lanza E (1993) Carotenoid content of fruit and vegetables: an evaluation of analytical data. J Am Diet Assoc 93, 284-296.

26. Tucker KL, Chen H, Vogel S, Wilson PW, Schaefer EJ \& Lammi-Keefe CJ (1999) Carotenoid intakes, assessed by dietary questionnaire, are associated with plasma carotenoid concentrations in an elderly population. J Nutr 129, 438-445.

27. McNaughton SA, Marks GC, Gaffney P, Williams G \& Green A (2005) Validation of a food-frequency questionnaire 
assessment of carotenoid and vitamin E intake using weighed food records and plasma biomarkers: the method of triads model. Eur J Clin Nutr 59, 211-218.

28. Forman MR, Lanza E, Yong LC, Holden JM, Graubard BI, Beecher GR, Meltiz M, Brown ED \& Smith JC (1993) The correlation between two dietary assessments of carotenoid intake and plasma carotenoid concentrations: application of a carotenoid food-composition database. Am J Clin Nutr $\mathbf{5 8}, 519-524$.

29. Yong L, Forman MR, Beecher GR, Graubard BI, Campbell WS, Reichman ME, Taylor PR, Lanza E, Holden JM \& Judd JT (1994) Relationship between dietary intake and plasma concentrations of carotenoids in premenopausal women: application of the USDA-NCI carotenoid food-composition database. Am J Clin Nutr 60, 223-230.

30. El-Sohemy A, Baylin A, Kabagambe E, Ascherio A, Speigelman D \& Campos H (2002) Individual carotenoid concentrations in adipose tissue and plasma as biomarkers of dietary intake. Am J Clin Nutr 76, 172-179.

31. Rock CL, Flatt SW, Wright FA, Faerber S, Newman V, Kealey S \& Pierce JP (1997) Responsiveness of carotenoids to a high vegetable diet intervention designed to prevent breast cancer recurrence. Cancer Epidemiol Biomarkers Prev 6, 616-623.

32. van het Hof $\mathrm{KH}$, West CE, Weststrate JA \& Hautvast JG (2000) Dietary factors that affect the bioavailability of carotenoids. J Nutr 130, 503-506.

33. Fielding JM, Rowley KG, Cooper P \& O'Dea K (2005) Increases in plasma lycopene concentration after consumption of tomatoes cooked with olive oil. Asia Pac J Clin Nutr 14, 131-136.

34. Gartner C, Stahl W \& Sies H (1997) Lycopene is more bioavailable from tomato paste than from fresh tomatoes. Am J Clin Nutr 66, 116-122.
35. Michaud DS, Feskanich D, Rimm EB, Colditz GA, Speizer FE \& Willett WC (2000) Intake of specific carotenoids and risk of lung cancer in 2 prospective US cohorts. Am J Clin Nutr 72, 990-997.

36. Al-Delaimy WK, Ferrari P, Slimani N et al. (2005) Plasma carotenoids as biomarkers of intake of fruits and vegetables: individual-level correlations in the European Prospective Investigation into Cancer and Nutrition (EPIC). Eur J Clin Nutr 59, 1387-1396.

37. Coyne T, Ibiebele TI, McNaughton SA, Rutishauser IHE, O'Dea K, Hodge AM, McClintock C, Findlay MG \& Lee A (2005) Evaluation of brief dietary questions to estimate vegetable and fruit consumption - using serum carotenoids and red-cell folate. Public Health Nutr 8, 298-308.

38. Gibson RS (1990) Principles of Nutritional Assessment. New York: Oxford University Press.

39. Willett WC, Stampfer MJ, Underwood BA, Speizer FE, Rosner B \& Hennekens CH (1983) Validation of a dietary questionnaire with plasma carotenoid and $\alpha$-tocopherol levels. Am J Clin Nutr 38, 631-639.

40. El-Sohemy A, Baylin A, Ascherio A, Kabagambe E, Spiegelman D \& Campos H (2001) Population-based study of $\alpha$ - and $\gamma$-tocopherol in plasma and adipose tissue as biomarkers of intake in Costa Rican adults. Am J Clin Nutr 74, 356-363.

41. Brunner E, Stallone D, Juneja M, Bingham S \& Marmot M (2001) Dietary assessment in Whitehall II: comparison of $7 \mathrm{~d}$ diet diary and food-frequency questionnaire and validity against biomarkers. BrJ Nutr 86, 405-414.

42. Kardinaal AF, van't Veer P, Brants HA, van den Berg H, van Schoonhoven J \& Hermus RJ (1995) Relations between antioxidant vitamins in adipose tissue, plasma, and diet. Am J Epidemiol 141, 440-450. 